\title{
Technical and Professional Communication for Chemical Engineers
}

\section{Elif Miskioglu, The Ohio State University}

Elif Miskioglu graduated from Iowa State with a B.S. in Chemical Engineering and minor in Genetics. She is currently a $\mathrm{PhD}$ candidate at The Ohio State University, where she is studying learning styles in the chemical engineering undergraduate student population. 


\section{Technical and Professional Communication for Chemical Engineers}

\section{Abstract}

Good communication skills are vital for any career. Engineers are often stigmatized as being poor communicators, and while this is merely a stereotype, many engineers and STEM students do express disinterest in writing and other forms of communication. While communication is incorporated in many undergraduate chemical engineering courses through laboratory reports, presentations, and informal short answer questions, these items are generally evaluated for their technical accuracy, not on aspects of their delivery and presentation. In the chemical engineering department of a large Midwestern university, students are required to take two courses in writing and communication. The first is a general English course, the second is an elective. While technical communication is an option for this elective, so are courses in fairy-tale literature or the writings of various ethnicities. Thus, students are not explicitly required to take a course in technical communication, but rather expected to gain these skills needed for their professional careers through other coursework and external experiences. Other departments at the same institution offer discipline-specific courses in technical communication, and informal observations of the communication skills of senior-level students have suggested that our department may benefit from such a course. In Spring 2014, we piloted an undergraduate course, Technical and Professional Communication for Chemical Engineers, and with its success the course is currently being offered in Spring 2015. Course focus is on all aspects of communication, verbal (written and oral), non-verbal (body language and development of visuals), and professional skills (e.g., resume development, e-mail writing). The format of the course is heavily active and inquiry-based learning, with short lectures guiding the 80 minute sessions. A typical session generally consists of a warm-up activity that gauges the student perceptions and knowledge of the topic of interest, then a brief lecture and discussion on the topic, followed by a second activity that allows the students to practice the concepts discussed in the lecture portion. This model was adopted based on the expectation that students will enter the course with varying schemata regarding communication, each derived from varied individual experiences. The warm-up activity not only gets the students engaged in the topic from the start of class, but also serves as a guide for the lecture and discussion. Student responses to the course indicate that this is a high-value offering applicable for any chemical engineering student regardless of intended career path, and we look to establish this as a permanent course in the department. If and when the course enrollment becomes large enough, we are interested in comparing communication skills of students who have taken the course versus those who have not, through the addition of a communication specific evaluation of artifacts students are already required to develop in other department courses (the aforementioned items where evaluation is generally focused on technical accuracy). In this paper, we provide an outline of the course and student outcomes from the first offering.

\section{Motivation}

The ability to communicate effectively is one of the ABET student outcomes ${ }^{1}$, and arguably the most important skill for any professional, including engineers. In post-graduation surveys on the relevance of subjects and skills to career success, communication skills are identified as a skill graduates consider essential in several studies. ${ }^{2,3}$ It is a life-long learning process of practice and development. In our chemical engineering department, undergraduate students may graduate 
without ever having taken a formal course in technical communication. Laboratory and design reports, and associated presentations, are meant to provide students with essential technical communication experience, however, often these artifacts are evaluated more strongly on their technical merit as opposed to presentation and clarity of communication. Clear and effective presentation, however, is vital to a successful engineering career. Noting an opportunity to expand our course offerings in an effort to develop more prepared chemical engineers, in the Spring of 2014 we piloted a 3-credit course entitled Technical and Professional Communication for Chemical Engineers.

\section{Course Goals and Objectives}

This course was approached utilizing the Backwards Design methodology, beginning with what we wanted the student to gain by the completion of the course. Since communication is a subject in which the students will likely have highly variable backgrounds and needs, the desire was to create a course with enough flexibility and focus on growth so that each student may improve in the areas most applicable to them, while continuing to develop and practice areas that are already strengths. The course goals and objectives are listed in Table 1.

Table 1. Summary of course goals and corresponding objectives.

\begin{tabular}{|c|c|c|}
\hline & $\begin{array}{l}\text { Course Goals: Upon completion of } \\
\text { this course, students will... }\end{array}$ & Learning Objectives \\
\hline 1 & $\begin{array}{l}\text { understand the importance of effective } \\
\text { communication in all aspects of their work } \\
\text { and life. }\end{array}$ & $\begin{array}{l}\text { Students will integrate concepts into their } \\
\text { daily life and participate in communication } \\
\text { building practices/activities. Students will } \\
\text { evaluate communication experiences } \\
\text { (through reflection) and predict possible } \\
\text { outcomes of communication scenarios } \\
\text { (positive and negative). }\end{array}$ \\
\hline 2 & $\begin{array}{l}\text { view themselves as qualified to provide } \\
\text { constructive feedback in communication, } \\
\text { and understand the importance of } \\
\text { the constructive component. }\end{array}$ & $\begin{array}{l}\text { Students will evaluate others' work and } \\
\text { provide constructive feedback through peer } \\
\text { evaluation of course artifacts. }\end{array}$ \\
\hline 3 & $\begin{array}{l}\text { understand the importance of identifying the } \\
\text { significance of what they are } \\
\text { communicating, both big and small picture } \\
\text { and how they fit together. }\end{array}$ & $\begin{array}{l}\text { Students will identify the significance of } \\
\text { topic and differentiate between the big and } \\
\text { small picture. }\end{array}$ \\
\hline 4 & $\begin{array}{l}\text { be comfortable in identifying the audience in } \\
\text { their communication and appropriately } \\
\text { address them (in content and choice of } \\
\text { media, where choice is given). }\end{array}$ & $\begin{array}{l}\text { Students will identify their audience and } \\
\text { create communication appropriate for their } \\
\text { audience. }\end{array}$ \\
\hline
\end{tabular}




\begin{tabular}{|l|l|l|}
\hline 5 & $\begin{array}{l}\text { be confident in their ability to communicate } \\
\text { in a written, oral, or mixed media fashion. }\end{array}$ & $\begin{array}{l}\text { Students will synthesize technical artifacts as } \\
\text { appropriate for purpose (poster, proposal, } \\
\text { mixed media presentation, etc.). }\end{array}$ \\
\hline $\begin{array}{l}\text { be aware of their strengths and areas of } \\
\text { improvement in communication, and } \\
\text { understand that this is a life-long learning } \\
\text { process of practice and development. Ideally, } \\
\text { they will pursue opportunities to practice } \\
\text { varying types of communication (especially } \\
\text { those that are not prominent in their position) } \\
\text { to keep their skills sharp. }\end{array}$ & $\begin{array}{l}\text { Students will identify their strengths and } \\
\text { areas of improvement (demonstrate self- } \\
\text { awareness) and actively seek practice of } \\
\text { communication. }\end{array}$ \\
\hline
\end{tabular}

\section{Course Structure}

Technical and Professional Communication for Chemical Engineers meets for 80-minute sessions twice a week for 15 weeks. Each 80 minute session (except for presentation days) includes:

- "Items for the good of the order"-important updates, deadlines, and general instructor feedback regarding trends from class performance or engagement

- Introduction to the topic of the day

- Activity or open-ended question to establish the students' existing schemata towards the topic of the day

- Lecture and discussion on topic (emphasis on discussion)

- Activity to reinforce lecture and discussion points, as well as evaluate student gains from class

- Re-visiting any points deemed necessary from results of activity

Summary of Topics

Like many technical communication courses, the focus is on both oral and written communication. Audience analysis and communicating significance are two overarching themes that are woven into all topics throughout the course. These two topics are considered the most ubiquitous to effective communication, and important considerations in any communication task.

The topic of oral communication includes a variety of presentations, from impromptu to PowerPoint/Prezi and posters. While students are sometimes required to use a specific form of media for their presentation so they may gain experience with different options, there are also assignments in which they are asked to simply present using whatever media they deem most appropriate. Thus, guidelines for different forms of media and how to choose the most effective one for a certain purpose are discussed. Oral communication skills are further enhanced by activities that focus on specific common presentation problems and difficulties.

Topics in technical communication include active vs. passive voice, an overview of common grammar / spelling problems and conventions, presenting and interpreting data, critical reading and analysis of technical work, and plagiarism. These are covered through lectures and activities 
throughout the term, with a mixture of short (1/2 to 1 page) and longer ( 3 or more pages) writing assignments.

Professional communication contains a large breadth of topics, including writing resumes and cover letters, as well as interview skills. Business communication involves discussion of proper etiquette in business communication, including e-mails, as well as basics of executive summaries, memos, and other reports students may encounter in their careers.

On the first day of class, students are given a survey on communication background and selfefficacy. The survey aims to understand student perspectives on communication, experiences, career goals, and course expectations. The self-efficacy component of the survey provides information regarding the individual student's comfort with and attitude towards different aspects of communication, and this is repeated at the end-of-semester in a final survey. This before-and-after administration of the survey provides a means for measuring student growth during the course.

Peer and instructor feedback and opportunities for revision are built into the course structure, providing students opportunities to develop skills in becoming more effective in providing and receiving constructive criticism. Students provide peer-feedback both through structured routes where a set of guidelines is provided, and unstructured routes in which their own innate guidelines can be identified and expanded upon. Instructor feedback is provided on all tasks, either individually or in aggregate as general comments to the entire class.

Types of Assignments

Coursework consists of formal graded assignments, as well as informal exercises graded for participation. Several formal assignments lead into developing a brief proposal on a topic of student choice. The proposal assignment is open-ended; it may have a research, industry, business, or other STEM-related focus based on student interest. The topic is chosen by the student (and approved by the instructor) during the first third of the semester.

The formal assignments are listed and described below.

- Reflections - these consist of brief responses to a prompt and a series of questions related to a recent in-class topic. Students may be asked to revise a document and reflect on the process, watch a recording of a talk and comment on speaker delivery/style, critically analyze a piece of writing, etc. Reflection assignments are designed to reinforce important concepts from the week and challenge students to think more deeply about communication outside of the classroom. They are approximately $1 / 2$ to 1 -page, single spaced in paragraph form, and should at a minimum address the provided guiding questions. Grading for grammar and spelling is not strictly enforced on reflections, as they are meant to provide students a medium in which to freely write and express their thoughts. Emphasis of grading is on the understanding of concepts, depth of reflection, and clarity of expression (which may be impacted by grammar and spelling).

- Oral Presentations - a variety of oral presentation assignments occur throughout the term, providing students different opportunities to practice speaking in front of varying audiences.

○ Audience (Group) - the first formal presentation is a group assignment, allowing the students to feel less of the pressure of speaking in front of their class while 
providing the instructor an opportunity to learn about their oral presentation skills and styles. It occurs in the second or third week of class, and students are provided a prompt on which to focus their presentation. This presentation focuses on being aware of different types of audiences, emphasizing the concepts introduced in the first lecture of the class. Each group is assigned a different audience (but given the same prompt) and are free to choose their presentation persona. Groups are encouraged to be creative and have some fun with this assignment.

○ Powerpoint/Prezi (Individual)—slide design (graphics, backgrounds, font, etc.) is a topic covered in presentation delivery, and thus, in one individual presentation students are required to use PowerPoint or Prezi.

- Poster (Partner) - poster design and presentation, and situations where posters may be required or appropriate, is covered in the first half of the course. Pairs of students are tasked with creating a poster. For this assignment, the prompt asks the students to take on the role of K-12 science educators seeking funding to enhance their curriculum. Students are asked to prepare a 30 second pitch of their proposal, which they present in a mock poster session to reviewers (graduate students).

- Pitch / Proposal (Individual) — this final presentation of the course goes hand-inhand with the proposal assignment described further (below). Students are asked to present their proposal to a defined set of reviewers, as applicable to the topic, using the medium they deem most appropriate. Evaluation is on building a convincing argument, choice and development of appropriate media, and presentation skills.

- Critical Reading and Research Summary — similar to an annotated bibliography, this assignment requires students to begin the literature review for their proposal. Literature review, proposal writing, and developing an argument is discussed prior to this assignment. Students are asked to summarize three pieces of literature relevant to their topic, as well as comment on the relevance and how it may be useful in supporting their developing proposal.

- Abridged Review Paper - this is a summary of prior research that will then be revised as the background information for the student's proposal.

- Short Proposal - an open-ended assignment where students are asked to develop a proposal for research, industry, business, or another area of interest. Emphasis is on clear, concise technical writing and building a convincing argument with use of relevant supporting information and emphasis on significance of the proposal.

\section{Parameters for Student Evaluation}

Students are evaluated both against a rubric identifying features that define the quality of a communication artifact and on personal growth in communication. Because communication development requires active participation, and because the class period involves a high degree of active learning, both attendance and participation are components of the final grade. In the event of an absence, attendance points cannot be gained, however, participation points may be earned through completion of an alternative task that covers the learning objectives of the course. This reinforces the importance of attending class (i.e., professional situations), while understanding that perfect attendance is not always feasible. 
The parameters on which students are evaluated expands throughout the semester, allowing students to focus on building effective communication skills from one task to the next. In structured peer-feedback, the guidelines that students receive for evaluating their peers not only change to reflect the purpose of the assignment, but also expands as the term progresses, allowing students to strengthen their evaluation skills without overwhelming them in the beginning. Students may then better understand that evaluation is not a "one-size-fits-all" task, but rather something that is dynamic and directly influenced by what is being evaluated. In communication, the audience and significance are primary components of that.

\section{Feedback-Revision Cycles}

Feedback is an essential component of learning, and most effective when students are subsequently given a chance to respond to feedback. Opportunities for feedback and revision are built into the course model through drafting, peer review, and informal exercises that are reviewed by the instructor. Feedback may be individual or aggregate. All in-class exercises and activities are collected and/or reviewed by the instructor, after which aggregate feedback may be given to the class regarding points well understood and things that appear to have been missed. Individual feedback is provided regularly on all assignments, and required peer reviews offer another opportunity to receive feedback and revise. While not all assignments have a draft and final version, students are given an opportunity to redo all assignments that would otherwise receive low marks. The theory is that the student will learn more by working through revisions and discussing any points of confusion or disagreement with the instructor than they would by receiving a low grade and "recycling" their paper.

Throughout the semester there are required one-on-one meetings with the instructor to discuss communication and professional development. While students are welcome to meet with the instructor at any point in the semester, the required one-on-one meetings ensure that each student actually does meet with the instructor and has the opportunity to discuss their progress in the course. The meetings are often scheduled after a formal in-class presentation, and begin with asking the student to share their thoughts on how the presentation went and what areas of improvement they identify for themselves. Presentations are recorded, which allows the instructor to call attention to specific examples from the presentation while sharing both their own and peer feedback with the student. While the meeting focuses on the most recent presentation, this also serves as a time to check in with the student regarding overall growth in communication and experience in the course. Each meeting concludes with a breakdown of goals for the student to work toward for their next assignment, and feedback from the students may provide new or modified lecture/course items in the following weeks.

Active Learning and Inductive Teaching Activities

Students have been communicating their entire lives and often have a strong pre-existing schemata in topics of communication. Since experience tends to be the best educator, active learning and inductive teaching are the primary methods used in this course.

Early in each lecture there are opportunities for students to share their own pre-existing schemata for the topic of the day. This may manifest through open inquiry and discussion as a class, thinkpair-share, or a structured activity with a minimal prompt. Extracting pre-existing schemata allows the instructor to realize what the students already know and believe, and build upon this 
to strengthen concepts and combat misconceptions. In many cases, the instructor serves as a mediator and guide for the students in developing conceptual understanding.

Examples of activities designed to draw out students' existing schemata and develop a common schemata include:

- Poster Drafting - students are given a prompt for a poster to draft. With a partner, they work on an 8.5 X 11 " mock-up of their poster, with no prior discussion as to the purpose or design of posters. Pairs then translate their mock-ups onto the board for their peers, and the class discusses common components and key differences between designs before establishing a new "best mock-up" together. This guides discussion of why certain components are necessary for the poster, why they are arranged where they are, what else needs to be considered, and how a different prompt may result in a different poster. The final outcome is a general set of guidelines for poster design that the students developed themselves, with mediation from the instructor.

- Proposal Writing - students are given a topic on which to write a proposal and asked to develop a proposal outline. They are next asked to pair up with partner and compare/contrast their outlines. After some discussion, partners share differences and similarities with the class while the instructor captures components of the students' outlines on the board. At this point, the students are asked what the purpose of the proposal is, and following discussion and agreement, told to revise their proposal outline to better emphasize the purpose. This is again done in think-pair-share, and at the completion of sharing, the class will have generated their own outline of the components of a proposal, and have participated in instructor-led discussion regarding what each component entails.

To improve communication skills, practice is essential, and many active-learning activities are focused around the opportunity to practice and immediately respond to feedback. These activities are mainly focused on presentation skills, but include a few writing activities as well. Examples are:

- Eliminating Fillers - a series of impromptu speeches is used to help students focus on identifying their use of fillers ("uh," "umm...," "you know," "so," etc.). Early in the semester, students are asked to submit a list of five topics they consider themselves knowledgeable in. This activity uses these topics, and in the first round the instructor randomly picks a topic for each student to speak about. The student is given 30 seconds to think before the clock begins, after which they speak for two minutes and their filler words are counted. This provides their "filler words per minute" baseline. In the second round, students are told that their goal is now to go one full minute without saying a filler word. If they succeed, they are exempt from future rounds and get to observe other students. Before each second round speech begins, the student is given their "fillers per minute" score from round one and their new topic. As soon as a filler word is uttered or one minute elapses, whichever comes first, time is recorded and the speech is over. This activity promotes student awareness of fillers, and has been effective in helping students who have high use of fillers improve over the semester. Discussion of practices that helped students reduce fillers usually highlights slower and more deliberate speech as key strategies. 
- Reading off Slides - this is another set of impromptu speeches in which slides are prepared by the instructor on the campus/community topics students consider themselves to know well (also provided to the instructor at the beginning of the semester). The slides include a variety of designs, including text-heavy, visuals-heavy, good contrast, and poor contrast. The slides are compiled into a single presentation. The bottom of each slide has the words "Up next: [speaker's name]," with the next student speaker's name. When it is a student's turn, they advance to their slide (which they have never seen before), have 15 seconds to look at the slide, and then 30 seconds to speak without looking back at the slide. The number of "look backs" are recorded and reported after each round, and then there is discussion of what caused the students to look back. Common themes include simple unfamiliarity with the slide and factors of slide design, such as being text-heavy. Sometimes students succeed in not looking back at the slide, but their speech is unrelated to slide content; this is discussed as well. The activity reinforces the importance of deliberate preparation of any supplemental materials, like slides, for presentations, and the concept of making slides work for you. Often students limit themselves to reproducing slide designs they have seen in the past, rather than producing slide designs that allow them to present more comfortably.

- Eye Contact - this activity involves impromptu speeches in which speakers are tasked with making eye contact with every audience member (their peers and the instructor). After each student speaks, the class is asked if anyone felt that eye contact was not made with them, and this is noted. For this activity, the class is assigned specific seats, which are re-assigned after each round, to alter where the speaker must look. In some cases, students are seated right under the nose of the speaker, in others they are mostly focused on one area of the room with one or two placed elsewhere, away from the general mass of the class audience. This challenges the students to examine where their audience is seated before speaking, and to remember to engage the full classroom, not only where the greatest density lies.

- Caption Writing - students are presented with a figure or set of data to write a caption for. This is done in think (write)-pair-share, and after discussion on the data and what the caption should include, they are given time to revise their initial caption. Before ending the activity, students are asked what audience they wrote the caption for, and why they chose that audience. This is followed by a brief discussion of how the caption would change for a more or less technical audience, and whether the figure/data presentation itself would have to change as well.

- Business Communication Scenario, E-mail Version-students are presented with a workplace scenario which requires an e-mail to either a hypothetical boss, peer, or intern. Students compose a mock e-mail, then get in groups of three in which each person has written to a different audience (boss, peer, intern). In groups, they discuss the similarities and differences in their e-mail, and summarize the purpose of each communication. After sharing, each group rewrites all three e-mails together.

Active learning activities were developed by the instructor. Impromptu speeches are a commonly used form of practicing oral presentation skills, which provided the basis for the oral presentation skills activities. The basic format of an impromptu speech was modified to focus on specific areas of need identified in earlier teaching experience (instructional assistant for the graduate level research communication course). Writing activities were developed from student feedback; students reported desiring an increased number of short writing assignments to complete in class. 
Further, we continue to seek and build relationships with other institutions, departments, and individuals working to build active-learning in communication courses, and this can also serve as a source of new curricular ideas.

\section{Student Response}

In Spring 2014, 12 students enrolled in and completed the course. Currently, the Spring 2015 section has 18 students. The $50 \%$ increase in enrollment serves as a positive indicator regarding student response in 2014. On the 2015 first day survey, several students reported that they registered for the course based on recommendation from other students.

The 2014 students reported varying degrees of satisfaction with course components, as can be expected in a communication course when students have (completely) different backgrounds and needs. Several course components received unanimous praise, including the in-class presentation skills-development activities, and no components received unanimous disapproval. That is, every course component benefitted at least some portion of the students. Student evaluation of course goals unanimously reported that all course goals were addressed, and in only a few select cases did 1 of the 12 students think a goal was not achieved.

On the end-of-term survey, nearly all students reported increased confidence and notable improvement in technical writing and oral presentation skills, and most reported increased comfort with business communication. Table 2 compares the results from the first day and endof-term survey for the applicable questions as class averages. These results are from a Likerttype survey, where 1 corresponds to "Strongly Disagree" and 5 corresponds to "Strongly Agree." In most categories, there was an average increase in agreement with the prompt, with the notable exceptions of "giving oral presentations makes me nervous" and "I would like to improve my oral presentation skills." This suggests that students recognized a positive change in their oral presentation skills during the course, and this is further corroborated by the qualitative feedback discussed below. The greatest positive change reported is in student confidence of producing professional documents and providing peer feedback. In reporting class averages, the changes in individual self-efficacy are lost in the population. Thus, a matched-pairs student's t-test was performed to identify which areas showed a statistically significant difference in student response between the first and end-of-term surveys. For eight of the twelve prompts, the difference in student responses was significant at $\alpha=0.10$. These are indicated by an asterisk $(*)$ before the question.

Table 2. Average of class responses to first day and end-of-term surveys. Single asterisk (*) next to question indicates that student responses were significantly different between the first day survey and the end-of term survey by a matched pairs student's t-test with $\alpha=0.10$.

\begin{tabular}{|c|c|c|c|}
\hline \multirow{2}{*}{ Question } & \multicolumn{2}{|c|}{ Class Average } & \multirow{2}{*}{ Difference } \\
\cline { 2 - 3 } & First Day & $\begin{array}{c}\text { End-of- } \\
\text { Term }\end{array}$ & \\
\hline $\begin{array}{c}* \text { I am comfortable speaking in front of a small } \\
\text { audience (2 to 15 individuals). }\end{array}$ & 4.00 & 4.42 & 0.42 \\
\hline $\begin{array}{c}* \text { I am comfortable speaking in front of a } \\
\text { medium to large audience ( > 15 individuals). }\end{array}$ & 3.33 & 3.83 & 0.50 \\
\hline
\end{tabular}




\begin{tabular}{|c|c|c|c|}
\hline $\begin{array}{l}\text { *I can develop visual material (e.g., charts, } \\
\text { graphs, cartoons) with confidence. }\end{array}$ & 4.00 & 4.50 & 0.50 \\
\hline Giving oral presentations makes me nervous. & 3.17 & 2.96 & -0.21 \\
\hline $\begin{array}{c}\text { I understand how my body language, voice, and } \\
\text { personal presentation affects my } \\
\text { communication. }\end{array}$ & 4.17 & 4.54 & 0.38 \\
\hline $\begin{array}{l}\text { *I would like to improve my oral presentation } \\
\text { skills. }\end{array}$ & 4.58 & 3.91 & -0.67 \\
\hline *I am confident in my technical writing skills. & 3.33 & 3.92 & 0.58 \\
\hline $\begin{array}{l}\text { *I can produce professional documents for job } \\
\text { searching (resume, cover letter) with ease. }\end{array}$ & 3.33 & 4.17 & 0.83 \\
\hline $\begin{array}{l}\text { *I am confident and comfortable in daily } \\
\text { professional communication (e.g., e-mail } \\
\text { writing, informal presentations to a project team, } \\
\text { progress updates to supervisor). }\end{array}$ & 4.08 & 4.50 & 0.42 \\
\hline $\begin{array}{l}\text { *I am confident in editing and providing } \\
\text { constructive feedback of my peers' work. }\end{array}$ & 3.67 & 4.33 & 0.67 \\
\hline I would like to improve my writing skills. & 3.75 & 3.88 & 0.13 \\
\hline
\end{tabular}

The main course improvement suggested by the 2014 students was a greater number of short writing assignments. Overall, the class agreed that they believed their presentation skills to have improved to a greater degree than their writing. Thus, the 2015 version of the course offers more short writing assignments with specific focus on technical writing components (interpreting/explaining/presenting data, summarizing, etc.).

\section{Future Outlook}

To become a permanent offering in the department, the course must be taught by a faculty member. The developer and instructor for the course is a graduate student, who must ensure that all necessary materials are in place in order for the course to be sustainable. The $50 \%$ increase in enrollment between the first and second offering of the course implies that it provides a value that is recognized by the students. The instructor has been in discussion with other engineering departments that offer a similar communications-focused course both in an effort to leverage successful course components from each and discuss a potential path forward for making this a permanent offering in the chemical engineering department.

\section{Bibliography}

$1 \quad$ ABET. Criteria for Accrediting Engineering Programs. (2013).

2 Passow, H. J. Which ABET competencies do engineering graduates find most important in their work? Journal of Engineering Education 101, 95-118 (2012).

3 Sageev, P. \& Romanowski, C. J. A message from recent engineering graduates in the workplace: Results of a survey on technical communication skills. Journal of Engineering Education 90, 685-693 (2001). 